\title{
APPLICATION OF IN SILICO STUDIES TARGETING TELOMERIC G-QUADRUPLEX COMPLEX BY PERYLENE DIIMIDES FOR ANTICANCER THERAPY
}

\author{
HEMALATHA CN, VIJEY AANANDHI M* \\ Department of Pharmaceutical Chemistry and Analysis, School of Pharmaceutical Sciences, Vels Institute of Science, Technology and \\ Advanced Studies, Chennai, Tamil Nadu, India. Email: hodpchemistry@velsuniv.ac.in
}

Received: 10 October 2018, Revised and Accepted: 11 December 2018

\section{ABSTRACT}

Objective: Telomerase enzyme which is expressed in detectable levels and its mechanism was that it increases the length when it binds to telomeres. This eventually leads to extension of lifespan of cells and also makes an attractive target for cancer therapy. Perylene diimides bind to telomerase with duplex genomic DNA, and these G-quadruplex ligands are of responsible for binding affinity with respective proteins. Based on the $\mathrm{IC}_{50}$ values of perylene diimides, QSAR has been studied out and the results are elaborated in preliminary research works. From the results of QSAR, the selected perylene ligands are selected for docking choosing telomerase as a target/protein. From the results of in silico studies, new compounds are designed and synthesized accordingly. Now, the objective of the study was to dock the final synthesized compounds with the telomerase protein to study regarding the pKi value using G-quadruplex ligand database (G4LDB). The docked results are visualized using Discovery Studio Visualizer 4.1. The results are compared with the standard N,N'-bis-(2-(1-piperidino)ethyl)-3,4,9,10-perylene tetracarboxylic acid diimide (PIPER) drug and these compounds will be effective for anticancer therapy.

Methods: The study was to investigate the docking results of synthesized perylene compounds with the results from G4LDB and visualized by Discovery Studio 4.1 Visualizer. The telomerase proteins selected for the study were extracted from Protein Data Bank, and the proteins selected for the study are 3SC8 and 3CE5. Among the compounds (R1, R2, R3, and R4) screened in G-Quadruplex Ligand Database, compound R3 shows better binding affinity with good pKi value as well the interactions with the protein and ligand show better affinity with the targets and these are compared with the standard drug PIPER drug.

Results: Compound R3 possesses the best binding affinity with the target 3CE5 and 3SC8 which shows that the compound will be effective for anticancer therapy.

Keywords: AutoDock, G-Quadruplex ligand database, Docking, Perylene derivatives.

(C) 2018 The Authors. Published by Innovare Academic Sciences Pvt Ltd. This is an open access article under the CC BY license (http://creativecommons. org/licenses/by/4. 0/) DOI: http://dx.doi.org/10.22159/ajpcr.2018.v11s4.31680

\section{INTRODUCTION}

G-Quadruplex stabilization promotes apoptosis

G-Quartets are square planar arrangements of four guanine bases [1-5] and these are stable stacks in macromolecule sequences [6-8]. These structures are G-quadruplexes which contain purine tetrads [9]. G-quadruplexes area unit four-stranded guanine-wealthy DNA structures present at the telomeric ends [10]. G-Quadruplex stabilization leads to inhibition of the telomerase activity, which induces the apoptosis [11,12]. The compounds such as PDI, NDI, and hexazole are the possible intercalators acting on the G-quartet structure and stabilize it. For eg: Cationic porphyrin, Quindoline, Berberine and trisubstitutes iso-alloxazines have been incontestable to interfere with the oncogenic transcription invitro [13-15].

The compounds are docked using G-quadruplex ligand database (G4LDB). The G4LDB online docking proceeds as the compounds are converted from two dimensional to three dimensional. This module incorporated 28 docking models of G-quadruplexes. Once ligand has been designed, job for docking has been submitted [16-18].

\section{METHODS}

\section{G4LDB}

The four synthesized perylene compounds are docked using G-Quadruplex Ligand Database. The perylene compounds are tabulated in Table 1.

In step one, perylene compounds are drawn and the structures are converted to simplified molecular-input line-entry system (SMILES) format using online SMILES translator. In step two, the target (3CE5 and 3SC8) was chosen and the compounds in SMILE format were given for computation. The process will take 15-20 min for completion of the docking job. The results are finally downloaded and the complex. Protein data bank (PDB) structures are visualized using Discovery Studio Visualizer 4.1.

N,N'-bis-(2-(1-piperidino)ethyl)-3,4,9,10-perylene tetracarboxylic acid diimide (PIPER), the standard compound, was downloaded from the same module and computed for docking with the two selected targets (3CE5 and 3SC8) to get to know about the best binding affinity toward the perylene and its ligands [19-21]. The targets selected for the study are as follows: 3CE5 and 3SC8.

The four compounds are docked with the two targets (3CE5 and 3SC8) and compared with the PIPER compound. The results are tabulated in Table 2. Among the four perylene compounds, compound R3 showed good $\mathrm{pKi}$ value when compared with the PIPER compound which shows that these compounds possess highest binding affinities and these compounds are represented in Fig. 1.

The hydrogen bond interactions with the enzyme and the ligand are tabulated in Tables 3 and 4 .

\section{RESULTS}

Docking has been done by G-Quadruplex Ligand Database. This is an online database which was having inbuilt tools and performed by Open Babel 2.3.0 to predict the binding affinity with the targets [22]. The targets (3CE5 and 3SC8) for the docking are selected based on the 
Table 1: Structure of novel perylene diimides target molecules

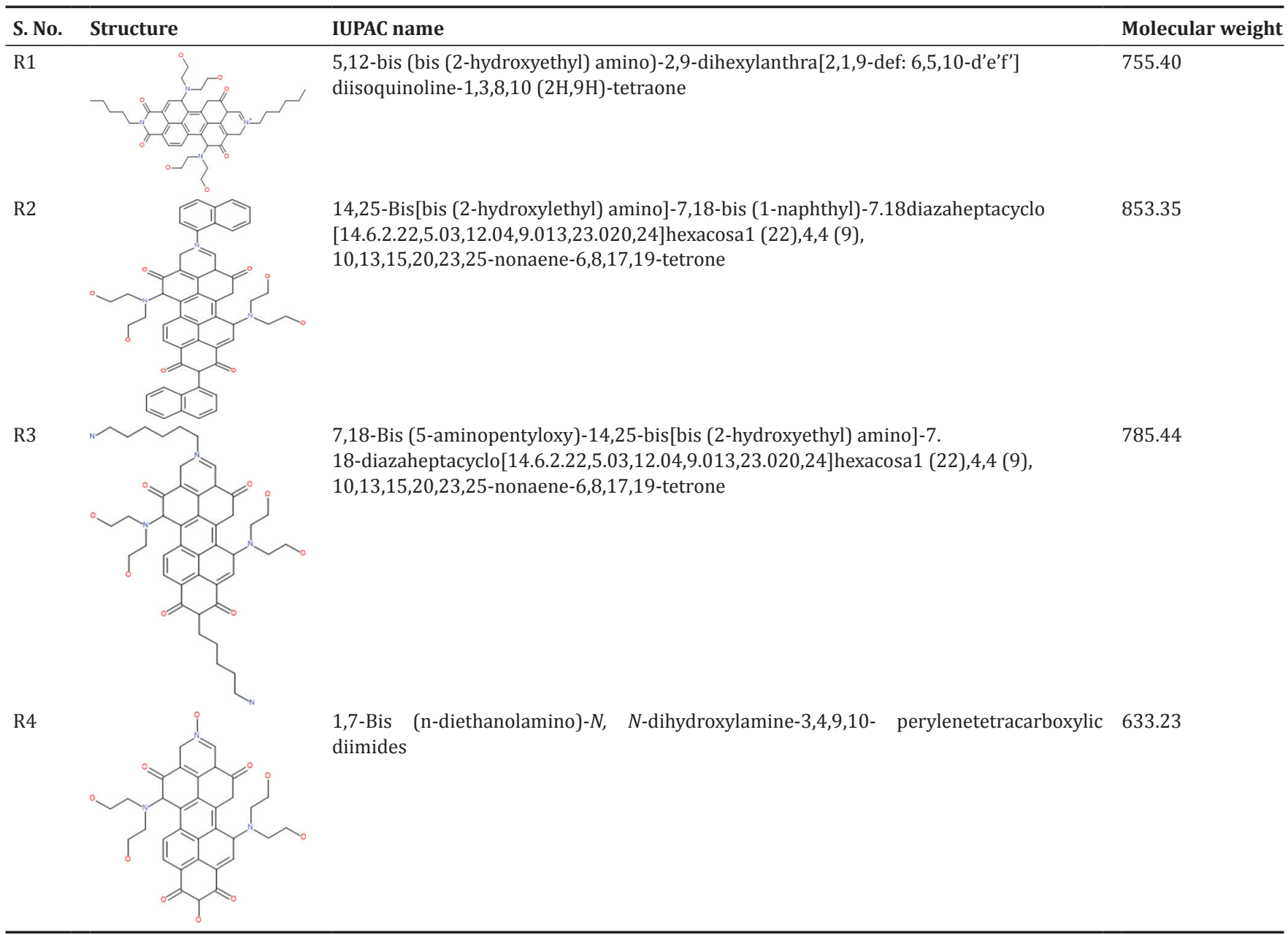

Table 2: Results of pKi value for the four synthesized perylene compounds

\begin{tabular}{llll}
\hline S. No & Compound & \multicolumn{2}{l}{ Target PDBs } \\
\cline { 3 - 4 } & & $\mathbf{3 C E 5}$ & $\mathbf{3 S C 8}$ \\
\hline 1 & R1 & 4.58 & 4.59 \\
2 & R2 & 2.71 & 2.3 \\
3 & R3 & 5.22 & 5.55 \\
4 & R4 & 4.45 & 4 \\
5 & PIPER & 8.84 & 8.02 \\
\hline
\end{tabular}

PIPER: N, N'-bis-(2-(1-piperidino) ethyl)-3,4,9,10-perylene tetracarboxylic acid diimide, PDB: Protein data bankm

literature survey, and the four synthesized perylene compounds are docked. From the results, compound R3 is selected and the results of these compounds are visualized using Discovery Studio 4.1 Visualizer.

\section{DISCUSSION}

From the docking results of G-Quadruplex Ligand Database, compound R3 showed good inhibitory constant pKi value which shows the correlation coefficient and proves that the perylene derivatives will be efficient with the targets (3CE5 and 3SC8).

\section{CONCLUSION}

Based on the research work, we selected a set of perylene compounds by analyzing the $\mathrm{IC}_{50}$ values from literature survey. QSAR study has been done, and from the results, new compounds are designed from

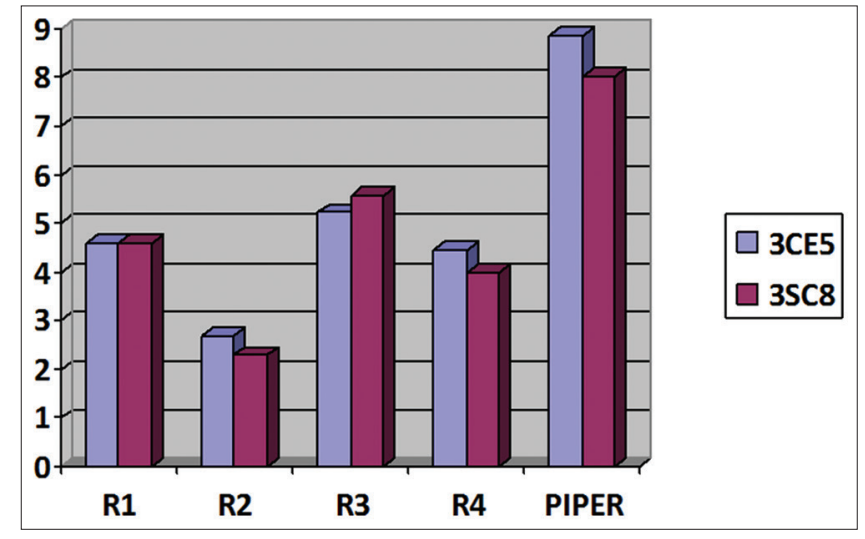

Fig. 1: Results of pKi value for the four synthesized perylene compounds

the QSAR equation, and hence, new compounds are designed and biological activity values are predicted. The designed compounds are screened using computational studies using selective targets from PDB, and a scaffold was selected for synthesis. We synthesized four perylene compounds and docked using G-Quadruplex Ligand Database to find the inhibitory value and hydrogen bond interactions with the ligand. The results are tabulated, and among the four perylene compounds, compound R3 showing more potent, the selected best compound R3 targeting the telomerase enzyme, may be used for in vivo studies which will be effective for anticancer therapy. 
Table 3: Hydrogen bond interactions with the enzyme and the ligands - 3CE5

\begin{tabular}{llll}
\hline S. No & Compound & 3CE5 & \\
\hline 1 & R3 & & \\
& & & \\
& & &
\end{tabular}

PIPER: N, N'-bis-(2-(1-piperidino) ethyl)-3,4,9,10-perylene tetracarboxylic acid diimide

Table 4: Hydrogen bond interactions with the enzyme and the ligands - 3CS8

\begin{tabular}{|c|c|c|}
\hline S. No & Compound & $3 S C 8$ \\
\hline 1 & R3 & \\
\hline 2 & PIPER & \\
\hline
\end{tabular}

\section{ACKNOWLEDGMENTS}

The authors are thankful to Vels Institute of Science, Technology and Advanced Studies and its management for providing research facilities and encouragement.

\section{AUTHORS' CONTRIBUTIONS}

The authors are equally contributed for the research work and preparing the manuscript.

\section{CONFLICTS OF INTEREST}

The authors declare no conflicts of interest.

\section{REFERENCES}

1. Banu S, Bollu R, Bantu R, Nagarapu L, Polepalli S, Jain N, et al. Design, synthesis and docking studies of novel 1,2-dihydro-4hydroxy-2-oxoquinoline-3-carboxamide derivatives as a potential antiproliferative agents. Eur J Med Chem 2017;125:400-10.

2. Hemalatha C,Vijey M, Aanandhi VM. G-Quadruplex ligands as stabilizer targeting telomerase as anti-cancer agents. Asian J Pharm Clin Res 2017;10:50-3.

3. Hemalatha C, Muthukumar V. Application of 3D QSAR and docking studies in optimization of perylene diimides as anti-cancer agent. Indian J Pharm Educ Res 2018;52:666-75.

4. Hemalatha C, Aanandhi MV. 3D QSAR and docking study of perylenedi imides analogues as potent apoptosis inducer and efficacious anticancer agent. Indian Drugs 2017;54:15-27.

5. Hemalatha C, Aanandhi MV. Synthesis of some novel perylene di imides and evaluation of their anti cancer activity. Asian J Pharm Clin Res 2018;11:1-9.

6. Marco DI, Antonio A, Rodriguez RA, Balasubramanian S. Experimental approaches to identify cellular G-quadruplex structures and functions. Methods 2012;57:84-2.

7. Sen D, Gilbert W. Formation of parallel four-stranded complexes by guanine-rich motifs in DNA and its implications for meiosis. Nature 1988;334:364-6.

8. Davis JT. G-quartets 40 years later: From 5'-GMP to molecular biology and supramolecular chemistry. Angew Chem Int Ed Engl 2004;43:668-98.

9. Tracy M. Brya, Peter Baumann. G-Quadruplexes: From Guanine Gels to Chemotherapeutics. Mol Biotechnol 2011; 49:198-08.

10. Patel DJ, Phan AT, Kuryavyi V. Human telomere, oncogenic promoter and 5'-UTR G-quadruplexes: Diverse higher order DNA and RNA targets for cancer therapeutics. Nucleic Acids Res 2007;35:7429-55.

11. Siddiqui-Jain A, Grand CL, Bearss DJ, Hurley LH. Direct evidence for a G-quadruplex in a promoter region and its targeting with a small molecule to repress c-MYC transcription. Proc Natl Acad Sci U S A 2002;99:11593-8.

12. Grand CL, Han H, Muñoz RM, Weitman S, Von Hoff DD, Hurley LH, et al. The cationic porphyrin TMPyP4 down-regulates c-MYC and human telomerase reverse transcriptase expression and inhibits tumor growth in vivo. Mol Cancer Ther 2002;1:565-73.

13. Lu YJ, Ou TM, Tan JH, Hou JQ, Shao WY, Peng D, et al. 5-N-methylated quindoline derivatives as telomeric g-quadruplex stabilizing ligands: Effects of 5-N positive charge on quadruplex binding affinity and cell proliferation. J Med Chem 2008;51:6381-92.

14. Bejugam M, Sewitz S, Shirude PS, Rodriguez R, Shahid R, Balasubramanian $\mathrm{S}$, et al. Trisubstituted isoalloxazines as a new class of G-quadruplex binding ligands: Small molecule regulation of c-kit oncogene expression. J Am Chem Soc 2007;129:12926-7.

15. Duan W, Rangan A, Vankayalapati H, Kim MY, Zeng Q, Sun D, et al. Design and synthesis of fluoroquinophenoxazines that interact with human telomeric G-quadruplexes and their biological effects. Mol Cancer Ther 2001;1:103-20.

16. Li Q, Xiang JF, Yang QF, Sun HX, Guan AJ, Tang YL, et al. G4LDB: A database for discovering and studying G-quadruplex ligands. Nucleic Acids Res 2013;41:D1115-23.

17. Chu B, Yuan G, Zhou J, Ou Y, Zhu P. A new telomerase inhibitor and apoptosis-inducing agent in leukemia: Perylene derivative as G-quadruplex ligand Te103. Drug Dev Res 2008;69:235-41.

18. Read MA, Wood AA, Harrison JR, Gowan SM, Kelland LR, Dosanjh HS, et al. Molecular modeling studies on G-quadruplex complexes of telomerase inhibitors: Structure-activity relationships. J Med Chem 1999;42:4538-46.

19. Fedoroff OY, Salazar M, Han H, Chemeris VV, Kerwin SM, Hurley LH, et al. NMR-based model of a telomerase-inhibiting compound bound to G-quadruplex DNA. Biochemistry 1998;37:12367-74.

20. Rossetti L, Franceschin M, Schirripa S, Bianco A, Ortaggi G, Savino M, et al. Selective interactions of perylene derivatives having different side chains with inter- and intramolecular G-quadruplex DNA structures. A correlation with telomerase inhibition. Bioorg Med Chem Lett 2005; 15:413-20.

21. Franceschin M, Pascucci E, Alvino A, D’Ambrosio D, Bianco A, Ortaggi $\mathrm{G}$, et al. New highly hydrosoluble and not self-aggregated perylene derivatives with three and four polar side-chains as G-quadruplex telomere targeting agents and telomerase inhibitors. Bioorg Med Chem Lett 2007;17:2515-22.

22. Franceschin M, Lombardo CM, Pascucci E, D'Ambrosio D, Micheli E, Bianco A, et al. The number and distances of positive charges of polyamine side chains in a series of perylene diimides significantly influence their ability to induce G-quadruplex structures and inhibit human telomerase. Bioorg Med Chem 2008; 16:2292-304. 